\title{
Gut Microbiota and Fecal Metabolome Perturbation in Children with Autism Spectrum Disorder
}

\author{
Ashraf Mohamadkhani ${ }^{1, *}$
}

1. Liver and Pancreatobiliary Diseases Research Center, Digestive Disease Research Institute, Shariati Hospital, Tehran University of Medical Sciences, Tehran, Iran

\footnotetext{
* Corresponding Author: Ashraf Mohamadkhani, Ph.D Liver and Pancreatobiliary Diseases Research Center, Digestive Disease Research Institute, Shariati Hospital, Tehran University of Medical Sciences, Tehran, Iran Tel: + 982182415780

Fax: + 982182415400

Email: mohamadkhani.ashraf@gmail.com

Received: 05 Mar. 2018

Accepted: 18 Jul. 2018
}

\section{ABSTRACT}

The brain-intestinal axis concept describes the communication between the intestinal microbiota as an ecosystem of a number of dynamic microorganisms and the brain. The composition of the microbial community of the human gut is important for human health by influencing the total metabolomic profile. In children with autism spectrum disorder (ASD), the composition of the fecal microbiota and their metabolic products has a different configuration of the healthy child. An imbalance in the metabolite derived from the microbiota in children with ASD affect brain development and social behavior. In this article, we review recent discoveries about intestinal metabolites derived from microbiota based on high-yield molecular studies in children with ASD as part of the "intestinal brain axis".

\section{KEYWORDS:}

Autism spectrum disorder (ASD), Intestinal microbiota, Fecal metabolites, ASD children

Please cite this paper as:

Mohamadkhani A. Gut Microbiota and Fecal Metabolome Perturbation in Children with Autism Spectrum Disorder. Middle East J Dig Dis 2018;10:205-212. doi: 10.15171/ mejdd.2018.112.

\section{INTRODUCTION}

The development of intestinal microflora begins at birth and subsequently the colonization of bacterial composition in the human colon can be reached to more than 70 genera with about $95 \%$ belonging to four main phyla: Firmicutes, Bacteroidetes, Actinobacteria, and Protecteobacteria. ${ }^{1}$ The arrangement of gut microbiota in the first years of life is an important occasion in the development of the immune responses and in the production of vitamins. ${ }^{2,3}$ Low microbial diversity in the early stages of life leads to the onset of allergic diseases and defects in innate immune responses in older age. ${ }^{4}$ In the same way, the study of germ-free mice has shown that there must be a continuous association between the immune system and intestinal microbiota metabolites to keep the normal population of microglial in their brains. ${ }^{5}$ Among the non-communicable diseases, neuropsychiatric disorders are increasing worldwide. ${ }^{6}$ Intestinal dysbiosis is known as a risk factor for a series of neurodevelopmental disorders and psychological diseases such as autism spectrum disorder (ASD) and schizophrenia. ${ }^{7,8}$ Individuals with ASD show a wide range of characterizing repetitive behaviors and difficulties in social communication. Children with ASD show gastrointestinal (GI) symptoms such as abdominal pain, gaseousness, diarrhea, constipation, and flatulence, which are associated with the 
severity of ASD. ${ }^{6,89}$ Although the exact aetiology and pathology of ASD are not yet clear, the involvement of the microbiota and its metabolites in the pathophysiology of ASD received considerable attention. Genetic, environmental, and biological factors play a fundamental role in behavioral development during the mother's pregnancy and immediately after birth. ${ }^{10,11}$ Short chain fatty acids (SCFAs) produced by the intestinal microflora act as histone deacetylase inhibitors (HDAC), which modulate cellular gene expression related to neurotransmission systems. ${ }^{12}$ It has been shown that the treatment of stress-induced mice with beneficial bacteria such as Lactobacillus rhamnosus and Lactobacillus reuteri improved the poor social and cognitive behaviors by reducing stress-induced corticosterone and restored oxytocin. ${ }^{13,14}$ However, functional analysis such as metagenomics, metatranscriptomics, and metabolomics should follow studies of microbial composition. Metabolomics has the advantage of providing information on the final products of microbial functions, although most metabolomics studies focus on urine and blood metabolites. ${ }^{15,16}$

Metabolomics of fecal samples may provide clues to the intestinal microbial metabolism. In this article we recap on some of the recent studies on intestinal microbiota metabolites in early childhood with ASD.

\section{Colonization of intestinal microbiota in early life}

A typical human intestinal microbiota contains an unimaginable complexity of hundreds of phylotypes, with a great compositional diversity among individuals. ${ }^{2}$ Infants are born without gut microbiota, however, soon after birth, the gut is hosting with bacteria coming from the mother and the adjacent environment commonly belong to two main groups of anaerobic bacteria of Firmicutes and Bacteroidetes phyla. The dominant bacteria of the intestine are strictly anaerobic and highly sensitive to oxygen, and therefore the creation of extremely resistant spores during colonization allows them to spread in the host and in environmental diffusion. During the first year of life in response to the alteration of diet and environmental exposures, the composition of the microbiota contributes significant changes. ${ }^{8,17,18}$
However, the pattern of gut microbiota in children delivered by cesarean section (CS) differs from those that have been delivered vaginally. ${ }^{17,19}$ Intestinal microbiota scheme of children delivered through CS is accompanied by a delay or absence of Bacteroides in the first year of life, whereas children delivered vaginally (VD) showed diversity in Actinobacteria phylum. ${ }^{20,21}$ In about two years of life, the profiles of the children's intestinal microbiota are established to be similar to adults, although, the diet and factors such as exposure to antibiotics modify the characteristics of the intestinal microbiome. ${ }^{20,22}$ Human microorganisms reside in the GI tract in early life are essential modulators of the host's behavior. ${ }^{11}$ The intestinal microbiota is essential for human health to play a key role in bi-directional communication concerning the GI tract and the central nervous system. If the friendly bacteria in the gut are unbalanced, homeostasis related to bacterial by-products is disturbing and hypothetically leads to inappropriate mental health outcomes in the future life. ${ }^{23,24}$ Therefore, understanding the dynamics of behavior-gut associations in early childhood is important because numerous states of physical and mental health are implicated in the intestinal microbiome that is more flexible at infantile in contrast to the subsequent life. ${ }^{24}$

\section{Gut microbiota in the presence of ASD}

Recent findings show that the intestinal microbiota by involving metabolic pathways and employing immune system are responsible for ASD symptoms in children. ${ }^{25}$ GI symptoms, including constipation and diarrhea, are common in children with ASD, which are connected to behavioral terms, such as anxiety, self-injury, and aggression. ${ }^{9,26}$ Dysbiosis, changes in the proportion of primary bacterial phyla, is the manifestation of children with ASD. ${ }^{8}$ The intestinal microbiota of children with ASD are less different with the lowest level of Firmicutes. ${ }^{27}$

Using the next-generation sequencing technology, it has been shown that potentially useful phylotypes related to Prevotella, Coprococco, and unclassified Veillonellaceae in autism children with GI symptoms are failed. ${ }^{8,28}$ The amounts of Faecalibacterium with 
Table 1: Gut microbiota with lower quantity in children with ASD

\begin{tabular}{|c|c|c|c|}
\hline Genus/species & Characteristics & Bacteria Classification & Function \\
\hline $\begin{array}{l}\text { Prevotella, } \\
\text { Coprococcus }\end{array}$ & Gram-negative bacteria & $\begin{array}{c}\text { Bacteroidetes; Bacteroidetes; } \\
\text { Bacteroidales; Prevotellaceae; } \\
\text { Prevotella }\end{array}$ & $\begin{array}{l}\text { Oral and vaginal flora, its anaerobic } \\
\text { qualities allows it to grow successfully } \\
\text { in the human intestines }\end{array}$ \\
\hline Bifidobacterium & $\begin{array}{l}\text { Gram-positive, non-motile, often } \\
\text { branched anaerobic bacteria }\end{array}$ & $\begin{array}{c}\text { Actinobacteria; Actinobacteria; } \\
\text { Actinobacteridae; Bifidobacteriales; } \\
\text { Bifidobacteriaceae; Bifidobacterium }\end{array}$ & $\begin{array}{c}\text { Inhabitants of the gastrointestinal tract, } \\
\text { vagina, and mouth - Some } \\
\text { bifidobacteria are used as probiotics }\end{array}$ \\
\hline Faecalibacterium & & $\begin{array}{l}\text { Firmicutes; Clostridia;Clostridiales; } \\
\text { Clostridiaceae; Faecalibacterium }\end{array}$ & $\begin{array}{l}\text { Commensal bacteria of gut microbiota- } \\
\text { produce butyrate and other SCFAs }\end{array}$ \\
\hline Roseburia intestinalis & $\begin{array}{l}\text { anaerobic, gram-positive, slightly } \\
\text { curved rod-shaped and motile by } \\
\text { means of multiple subterminal flagella }\end{array}$ & $\begin{array}{c}\text { Firmicutes; Clostridia; } \\
\text { Clostridiales; Lachnospiraceae; } \\
\text { Roseburia; } R \text {. intestinalis }\end{array}$ & $\begin{array}{l}\text { a saccharolytic, butyrate-producing } \\
\text { bacterium first isolated } \\
\text { from human faeces }\end{array}$ \\
\hline
\end{tabular}

anti-inflammatory effect as well as ability to SCFAs synthesis and Roseburia intestinalis and Roseburia faecis with ability to starch degradation and carbohydrate fermentation to synthesize the SCFAs, are also defined at the lowest level in the fecal sample of children with ASD. ${ }^{29,30}$ The relative abundance of Haemophilus parainfluenzae was also lower in the feces of children with ASD. Furthermore Bifidobacterium with beneficial effect was reduced in children with ASD. ${ }^{31,32}$ Bacteria with lower frequency are presented in table 1 .

In contrast, an increase in the quantities of Lactobacillus, Clostridium, Bacteroidetes, Desulfovibrio, Caloramator, and Sarcina was detected in fecal samples of children with ASD and in a strong association with the severity of autism. The genus Lactobacillus, as probiotics, Prevotella with beneficial effect, and the harmful bacteria Sutterella, Enterococcus and Streptococcus thermophilus are abundant in ASD. ${ }^{33,34}$ Moreover, The genus of bacteria belongs to Bacteroidetes phyla such as Bacteroides, Barnesiella, Odoribacter, Parabacteroides, Prevotella, and Alistipes are more widespread. However, the Parasutterella genus of Proteobacteria phyla in addition to Proteobacteria is one of the most abundant phyla in the fecal samples of children with ASD. ${ }^{35,36}$ Bacterial species with higher frequency are shown in table 2. The Clostridiaceae species (Clostridium histolyticum cluster II and I) with ability to produce metabolic by-products such as phenols, p-cresol, and indole derivatives with toxic effects and Akkermansia muciniphila as a mucin degrading bacteria are present at life-threatening number in children with ASD. ${ }^{37,38}$

Candida (in particular Candida Albicans) is more abundant in the fecal samples of children with ASD, which results in carbohydrates and mineral absorption but releasing higher toxins. ${ }^{8,33}$ Candida produces ammonia and toxins that persuade autistic behaviors. The presence of Candida, that aggravates dysbiosis, is induced by alterations of bacterial microbiota in individuals with ASD. ${ }^{39}$

\section{Fecal metabolomic profile in children with ASD}

Almost all metabolomics studies in the context of autism have been conducted on urine and blood metabolites. ${ }^{15,16,24}$ The study of Persico and colleagues showed urinary p-cresol and sulfate conjugate derivative of $\mathrm{p}$-cresol regularly are present in autistic children and in contribution to worsening severity of autism. ${ }^{40}$ The other metabolites of intestinal microbiota such as SCFA, phenolic derivatives, and free amino acids (FAA) have the emotional impact on the behaviors of individuals with ASD. ${ }^{41}$ Higher urinary volatile organic compounds (VOCs) related to the intestinal microbiota in children with ASD have been also reported by Gevi and colleagues. ${ }^{15}$

Nonetheless, few studies have focused on fecal metabolites related to intestinal microbiota in children with ASD. The association of fecal p-cresol and phenolic substances containing p-cresol in children with autism has been reported in previous studies along with increased levels of p-cresol in the blood and urine. ${ }^{15,16,33,40} \mathrm{P}$-cresol that binds to human 
Table 2: Microbiota in the intestines of humans that are increased in children with ASD

\begin{tabular}{|c|c|c|c|}
\hline Genus/species & Characteristics & Bacteria Classification & Function \\
\hline Lactobacillus & $\begin{array}{c}\text { Gram-positive, facultative anaerobic } \\
\text { or microaerophilic, rod-shaped, } \\
\text { non-spore-forming bacteria }\end{array}$ & $\begin{array}{l}\text { Firmicutes; Bacilli; Lactobacillales; } \\
\text { Lactobacillaceae; Lactobacillus }\end{array}$ & Produce lactic acid, probiotic \\
\hline $\begin{array}{l}\text { Clostridium } \\
\text { histolyticum } \\
\text { cluster II and I }\end{array}$ & $\begin{array}{l}\text { Motile, gram-positive, } \\
\text { Strict anaerobe }\end{array}$ & $\begin{array}{l}\text { Firmicutes; Clostridia; Clostridiaceae; } \\
\text { Clostridium; C. histolyticum }\end{array}$ & $\begin{array}{l}\text { Secretes potent exotoxins, } \\
\text { pathogenesis of ulcerative colitis }\end{array}$ \\
\hline $\begin{array}{l}\text { Akkermansia } \\
\text { muciniphila }\end{array}$ & $\begin{array}{c}\text { Gram-negative, strictly anaerobic, } \\
\text { non-motile, non-spore-forming, } \\
\text { oval-shaped bacterium }\end{array}$ & $\begin{array}{c}\text { Verrucomicrobia; Verrucomicrobiae; } \\
\text { Verrucomicrobiales; Verrucomicrobiaceae; } \\
\text { akkermansia; } \text { A. muciniphila }\end{array}$ & Mucin-degrading bacterium \\
\hline Bacteroidetes & $\begin{array}{l}\text { Gram-negative, non-sporeforming, } \\
\text { anaerobic or aerobic, } \\
\text { and rod-shaped bacteria }\end{array}$ & $\begin{array}{c}\text { Bacteroidetes;Bacteroidia; } \\
\text { Bacteroidales;Bacteroidaceae; Bacteroides }\end{array}$ & $\begin{array}{l}\text { Abundant organism in the faeces } \\
\text { of warm-blooded }\end{array}$ \\
\hline Desulfovibrio & $\begin{array}{c}\text { Gram-negative sulfate-reducing } \\
\text { bacteria aerotolerant }\end{array}$ & $\begin{array}{c}\text { Proteobacteria; Deltaproteobacteria; } \\
\text { Desulfovibrionales; Desulfovibrionaceae; } \\
\text { Desulfovibrio }\end{array}$ & sulfate-reducing bacteria \\
\hline Caloramator & & $\begin{array}{l}\text { Firmicutes; Clostridia; Clostridiales; } \\
\text { Clostridiaceae; Caloramator }\end{array}$ & produced $p$-cresol \\
\hline Sarcina & Gram-positive cocci bacteria & $\begin{array}{c}\text { Firmicutes; Clostridia; Clostridiales; } \\
\text { Clostridiaceae; Sarcina }\end{array}$ & $\begin{array}{l}\text { A synthesizer of microbial } \\
\text { cellulose }\end{array}$ \\
\hline Enterococcus & $\begin{array}{l}\text { Gram-positive cocci } \\
\text { (diplococci or short chains) }\end{array}$ & $\begin{array}{l}\text { Firmicutes; Bacilli; Lactobacillales; } \\
\text { Enterococcaceae; Enterococcus }\end{array}$ & Common commensal organisms \\
\hline $\begin{array}{l}\text { Streptococcus } \\
\text { thermophilus }\end{array}$ & $\begin{array}{l}\text { Gram-positive bacterium, and } \\
\text { a fermentative facultative anaerobe }\end{array}$ & $\begin{array}{c}\text { Firmicutes; Bacilli; Lactobacillales; Strepto- } \\
\text { coccaceae; Streptococcus; S. thermophilus }\end{array}$ & Lactic acid bacterium \\
\hline Proteobacteria & Gram-negative bacteria & $\begin{array}{c}\text { Phylum: Proteobacteria } \\
\text { Include a wide variety of pathogens, such as } \\
\text { Escherichia, Salmonella, Vibrio, } \\
\text { Helicobacter, Yersinia, Legionellales, }\end{array}$ & produce phenol from tyrosine \\
\hline Candida & Genus of yeasts & $\begin{array}{c}\text { Fungi; Ascomycota; Saccharomycetes; } \\
\text { Saccharomycetales; } \\
\text { Saccharomycetaceae; Candida }\end{array}$ & $\begin{array}{l}\text { Commensals or endosymbionts } \\
\text { invade and cause disease when } \\
\text { mucosal barriers or the immune } \\
\text { system is disrupted }\end{array}$ \\
\hline $\begin{array}{l}\text { Ruminococcus } \\
\text { torques }\end{array}$ & $\begin{array}{l}\text { Gram-positive anaerobic } \\
\text { gut microbes }\end{array}$ & $\begin{array}{l}\text { Firmicutes; Clostridia; Clostridiales; } \\
\text { Ruminococcaceae; Ruminococcus }\end{array}$ & $\begin{array}{l}\text { Found in significant numbers in } \\
\text { the intestines of humans }\end{array}$ \\
\hline Sutterella spp. & Gram-negative rod bacteria & $\begin{array}{l}\text { Proteobacteria. Proteobacteria. } \\
\text { Burkholderiales; Sutterellaceae; Sutterella }\end{array}$ & $\begin{array}{l}\text { previously been isolated from } \\
\text { canine feces }\end{array}$ \\
\hline
\end{tabular}

serum albumin is produced from tyrosine or dietary toluene by some bacteria in the intestine. It has deleterious impact on the colon epithelial cell through DNA damage and is inversely associated with the presence of resistant starch in the diet. ${ }^{42,43}$ Increased intestinal permeability allows further communication by discharging microbiota metabolite and toxins from the intestine to the brain. ${ }^{44}$ For example, the main component of the cell wall of gram-negative bacteria, lipopolysaccharide (LPS), and other markers of immune-inflammatory activation in the serum may contribute to the pathophysiology of inflammation with a negative effect on social interaction in autism. ${ }^{45}$ Kang and co-workers in their recent study showed that the metabolite, isopropanol (or propan-2-ol) was the significant metabolite of stool that considerably increased in children with ASD..$^{33}$ Isopropanol is a neurotoxic organic solvent that irritates mucosal surfaces to induce GI complications. Alcohol dehydrogenase metabolizes isopropanol to acetone, propylene glycol, and acetate to be converted to glucose or other intermediary products. The predominant mechanism of action of isopropanol is major depression in the brain stem that subsequently affect central nervous system and lead to respiratory depression. ${ }^{46}$ Greater isopropanol levels in feces of children with ASD explain the function of species of lactic acid bacteria such 
Table 3: A list of key gut microbiota metabolite in children with ASD

\begin{tabular}{|c|c|c|c|}
\hline Metabolite & & Description & Structure \\
\hline p-Cresol (4-methylphenol) & $\uparrow$ & $\begin{array}{c}\text { The end-product of protein breakdown-metabolites of tyrosine, } \\
\text { phenylalanine, which are converted to } \\
\text { 4-hydroxyphenylacetic acid by intestinal bacteria }\end{array}$ & \\
\hline p-Cresol sulfate & $\uparrow$ & $\begin{array}{l}\text { A microbial metabolite that is found in urine and likely derives } \\
\text { from secondary metabolism of p-cresol and } \\
\text { is often considered to be a uremic toxin }\end{array}$ & \\
\hline $\begin{array}{l}\text { Isopropanol (Isopropyl } \\
\text { alcohol or 2-propanol) }\end{array}$ & $\uparrow$ & $\begin{array}{l}\text { Small amounts of this alcohol are produced naturally by gut micro- } \\
\text { bial flora. }\end{array}$ & \\
\hline Glutamate & $\uparrow$ & $\begin{array}{l}\text { It is found naturally primarily in the cell walls of certain bacteria } \\
\text { and in certain foods }\end{array}$ & \\
\hline $\begin{array}{l}\text { Gamma-aminobutyrate } \\
\text { (GABA) }\end{array}$ & & $\begin{array}{c}\text { An inhibitory neurotransmitter establish in the nervous systems of } \\
\text { many species- Low plasma GABA has been reported } \\
\text { in some depressed patients- aspartic acid and glutamic } \\
\text { acid probably inhibit GABA effects }\end{array}$ & \\
\hline Butyric acid & $\downarrow$ & $\begin{array}{l}\text { End-product of a fermentation process by obligate anaerobic } \\
\text { bacteria. Formed in the human colon by bacterial } \\
\text { fermentation of carbohydrates (dietary fiber), } \\
\text { and suppresses colorectal cancer (CRC) }\end{array}$ & \\
\hline Propionic acid & $\uparrow$ & $\begin{array}{l}\text { An end-product of the microbial digestion of } \\
\text { carbohydrates }\end{array}$ & \\
\hline
\end{tabular}

as Lactobacillus brevis, and Clostridium..$^{33,36}$ It was also observed that while neurotransmitters-glutamate was the highest in children with autism, the trends of gamma-aminobutyrate (GABA) concentrations were lower in feces of children with ASD. ${ }^{41}$ Large amounts of FAA from the hydrolysis of proteins and peptides that are created by proteolytic bacteria (e.g., Clostridium and Bacteroides) found in the fecal samples of children with ASD. ${ }^{29}$

Different types of SFCAs, as principal products of non-digestible carbohydrate fermentation by gut microbiota or by presence in the diet, show the increasing importance in healthy individuals. ${ }^{47}$ Commensal bacteria, such as Clostridia and Bifidobacteria produce SCFAs in the cecum and the colon that could bring into the hepatic, portal, and peripheral blood. ${ }^{48}$ De Angelis and colleagues ${ }^{41}$ and Adams and co-workers ${ }^{49}$ reported that total SCFAs with the exception of propionic and acetic acids reduced in the feces of children with ASD, however, Wang and others showed increased levels of SCFAs and ammonia in the fecal samples of children with ASD. In the study of Wang and colleagues when concentrations of fecal acetic, butyric, isobutyric, valeric, isovaleric, and caproic acids were assessed, all but caproic acid had a meaningfully higher level in children with ASD. ${ }^{50}$ Consistent with them, Adams and others presented children with ASD had significantly lower levels of SCFAs. The low level of SCFAs that was reported by Adams and others could possibly because of either lower production by beneficial bacteria or more absorption into the body as a result of increased gut permeability. SCFAs such as butyrate have significant benefits for human by developing the neurotransmitters and regulating the catecholaminergic biosynthesis by influencing the transcription of the tyrosine hydroxylase gene during life. ${ }^{51}$ SCFAs also modulate the expression 
of the host gene through inhibitor activity of histone deacetylase and epigenetic mechanism. Butyric acid acts as a potent inhibitor of histone deacetylase (HDAC) in the regulation of neurotransmitters dopamine, norepinephrine, and epinephrine. It also modulates the inflammatory and oxidative states of the intestinal mucosa. ${ }^{51,52}$ However animal studies have shown that propionic acid causes some autistic behaviors and compromised social manners. ${ }^{53}$ Similar effects of propionic acid to behavioral and electrographic derivation have been identified in humans. ${ }^{52}$ Propionic acid is mainly produced by Clostridia, Bacteroidetes, and Desulfovibrio, however Bifidobacterium, Faecalibacterium, Ruminococcus, and Eubacterium are positively correlated with butyric acids. ${ }^{50,52}$ Table 3 summarizes the intestinal metabolites that are reported in fecal sample of children with ASD.

\section{CONCLUSION}

In this review, we summarized the recent findings on faecal microbiota and related metabolites in children with ASD. It has been shown that Clostridiaceae species exist at the highest level in such children, which as principal bacterial groups, synthesize important organic neurotoxic metabolites such as phenols, p-cresol, and isopropanol. The application of high-yielding methods to recognize the fecal microbiota and the metabolites will support the control of an imbalance of the gut-brain axis in children with ASD and the implementation of new therapeutic strategies.

\section{ETHICAL APPROVAL}

There is nothing to be declared.

\section{CONFLICT OF INTEREST}

The author declares no conflict of interest related to this work.

\section{REFERENCES}

1. Kitsios GD, Morowitz MJ, Dickson RP, Huffnagle GB, McVerry BJ, Morris A. Dysbiosis in the intensive care unit: Microbiome science coming to the bedside. J Crit Care 2017;38:84-91. doi:10.1016/j.jcrc.2016.09.029.
2. Shreiner AB, Kao JY, Young VB. The gut microbiome in health and in disease. Curr Opin Gastroenterol 2015;31:69-75. doi:10.1097/MOG.0000000000000139.

3. Prentice S. They Are What You Eat: Can Nutritional Factors during Gestation and Early Infancy Modulate the Neonatal Immune Response? Front Immunol 2017;8:1641. doi:10.3389/fimmu.2017.01641.

4. Barros KV, Flor Silveira VL, Laranjeira MS, Wandalsen NF, Passeti S, de Oliveira R, et al. Evidence for Involvement of IL-9 and IL-22 in Cows' Milk Allergy in Infants. Nutrients 2017;9. doi:10.3390/nu9101048.

5. Erny D, Hrabe de Angelis AL, Jaitin D, Wieghofer P, Staszewski O, David E, et al. Host microbiota constantly control maturation and function of microglia in the CNS. Nat Neurosci 2015;18:965-77. doi:10.1038/nn.4030.

6. Babaknejad N, Sayehmiri F, Sayehmiri K, Mohamadkhani A, Bahrami S. The Relationship between Zinc Levels and Autism: A Systematic Review and Meta-analysis. Iran J Child Neurol 2016;10:1-9.

7. Severance EG, Prandovszky E, Castiglione J, Yolken RH. Gastroenterology issues in schizophrenia: why the gut matters. Curr Psychiatry Rep 2015;17:27. doi:10.1007/ s11920-015-0574-0.

8. Strati F, Cavalieri D, Albanese D, De Felice C, Donati C, Hayek J, et al. New evidences on the altered gut microbiota in autism spectrum disorders. Microbiome 2017;5:24. doi: 10.1186/s40168-017-0242-1.

9. Mazefsky CA, Schreiber DR, Olino TM, Minshew NJ. The association between emotional and behavioral problems and gastrointestinal symptoms among children with high-functioning autism. Autism 2014;18:493-501. doi: $10.1177 / 1362361313485164$

10. Mohamadkhani A. Genetics and its Approach in the Diagnosis of Diseases with Familial History. Govaresh 2017;21:211-20.

11. Latalova K, Hajda M, Prasko J. Can gut microbes play a role in mental disorders and their treatment? Psychiatr Danub 2017;29:28-30.

12. Kawanai T, Ago Y, Watanabe R, Inoue A, Taruta A, Onaka Y, et al. Prenatal Exposure to Histone Deacetylase Inhibitors Affects Gene Expression of Autism-Related Molecules and Delays Neuronal Maturation. Neurochem Res 2016;41:2574-84. doi:10.1007/s11064-016-1969-y.

13. Umbrello G, Esposito S. Microbiota and neurologic diseases: potential effects of probiotics. J Transl Med 2016;14:298. doi:10.1186/s12967-016-1058-7.

14. Bubnov RV, Babenko LP, Lazarenko LM, Mokrozub VV, Demchenko OA, Nechypurenko OV, et al. Comparative study of probiotic effects of Lactobacillus and Bifidobacteria strains on cholesterol levels, liver morphology and the gut microbiota in obese mice. EPMA J 2017;8:357-76. doi:10.1007/s13167-017-0117-3.

15. Gevi F, Zolla L, Gabriele S, Persico AM. Urinary metabolomics of young Italian autistic children supports abnormal tryptophan and purine metabolism. Mol Autism 2016;7:47. doi:10.1186/s13229-016-0109-5. 
16. West PR, Amaral DG, Bais P, Smith AM, Egnash LA, Ross ME, et al. Metabolomics as a tool for discovery of biomarkers of autism spectrum disorder in the blood plasma of children. PLoS One 2014;9:e112445. doi:10.1371/ journal.pone. 0112445 .

17. Neu J. Dysbiosis in the Neonatal Period: Role of Cesarean Section. Nestle Nutr Inst Workshop Ser 2017;88:57-66. doi:10.1159/000455215.

18. Thompson-Chagoyan OC, Maldonado J, Gil A. Colonization and impact of disease and other factors on intestinal microbiota. Dig Dis Sci 2007;52:2069-77. doi:10.1007/ s10620-006-9285-z.

19. Shin H, Pei Z, Martinez KA 2nd, Rivera-Vinas JI, Mendez $\mathrm{K}$, Cavallin $\mathrm{H}$, et al. The first microbial environment of infants born by $\mathrm{C}$-section: the operating room microbes. Microbiome 2015;3:59. doi:10.1186/s40168-015-0126-1.

20. de Moraes JG, Motta ME, Beltrao MF, Salviano TL, da Silva GA. Fecal Microbiota and Diet of Children with Chronic Constipation. Int J Pediatr 2016;2016:6787269. doi:10.1155/2016/6787269.

21. Gomez M, Moles L, Espinosa-Martos I, Bustos G, de Vos WM, Fernandez L, et al. Bacteriological and Immunological Profiling of Meconium and Fecal Samples from Preterm Infants: A Two-Year Follow-Up Study. Nutrients 2017;9. doi:10.3390/nu9121293.

22. Valles Y, Artacho A, Pascual-Garcia A, Ferrus ML, Gosalbes MJ, Abellan JJ,et al. Microbial succession in the gut: directional trends of taxonomic and functional change in a birth cohort of Spanish infants. PLoS Genet 2014;10:e1004406. doi:10.1371/journal.pgen.1004406.

23. Nair AT, Ramachandran V, Joghee NM, Antony S, Ramalingam G. Gut Microbiota Dysfunction as Reliable Non-invasive Early Diagnostic Biomarkers in the Pathophysiology of Parkinson's Disease: A Critical Review. J Neurogastroenterol Motil 2018;24:30-42. doi:10.5056/jnm17105.

24. Rajilic-Stojanovic M. Function of the microbiota. Best Pract Res Clin Gastroenterol 2013;27:5-16. doi:10.1016/j. bpg.2013.03.006.

25. Masi A, Breen EJ, Alvares GA, Glozier N, Hickie IB, Hunt A, et al. Cytokine levels and associations with symptom severity in male and female children with autism spectrum disorder. Mol Autism 2017;8:63. doi: 10.1186/ s13229-017-0176-2.

26. Buie T, Fuchs GJ 3rd, Furuta GT, Kooros K, Levy J, Lewis $\mathrm{JD}$, et al. Recommendations for evaluation and treatment of common gastrointestinal problems in children with ASDs. Pediatrics 2010;125 Suppl 1:S19-29. doi:10.1542/ peds.2009-1878D

27. Wu WL. Association Among Gut Microbes, Intestinal Physiology, and Autism. EBioMedicine 2017;25:11-2. doi:10.1016/j.ebiom.2017.10.013.

28. Tomova A, Husarova V, Lakatosova S, Bakos J, Vlkova B, Babinska $\mathrm{K}$, et al. Gastrointestinal microbiota in children with autism in Slovakia. Physiol Behav 2015;138:179-87. doi:10.1016/j.physbeh.2014.10.033.
29. De Angelis M, Francavilla R, Piccolo M, De Giacomo A, Gobbetti M. Autism spectrum disorders and intestinal microbiota. Gut Microbes 2015;6:207-13. doi: 10.1080/19490976.2015.1035855.

30. Kushak RI, Buie TM, Murray KF, Newburg DS, Chen C, Nestoridi E, et al. Evaluation of Intestinal Function in Children With Autism and Gastrointestinal Symptoms. $J$ Pediatr Gastroenterol Nutr 2016;62:687-91. doi:10.1097/ MPG.0000000000001174.

31. Hansakunachai T, Roongpraiwan R, Sombuntham T, Limprasert $P$, Ruangdaraganon N. A new structured interview for children with autism spectrum disorder based on the DSM-IV. J Med Assoc Thai 2014;97 Suppl 8:S7-14.

32. Wang L, Christophersen CT, Sorich MJ, Gerber JP, Angley MT, Conlon MA. Low relative abundances of the mucolytic bacterium Akkermansia muciniphila and Bifidobacterium spp. in feces of children with autism. Appl Environ Microbiol 2011;77:6718-21. doi:10.1128/AEM.05212-11.

33. Kang DW, Ilhan ZE, Isern NG, Hoyt DW, Howsmon DP, Shaffer M, et al. Differences in fecal microbial metabolites and microbiota of children with autism spectrum disorders. Anaerobe 2018;49:121-31. doi:10.1016/j.anaerobe.2017.12.007.

34. Wang L, Christophersen CT, Sorich MJ, Gerber JP, Angley MT, Conlon MA. Increased abundance of Sutterella spp. and Ruminococcus torques in feces of children with autism spectrum disorder. Mol Autism 2013;4:42. doi: $10.1186 / 2040-2392-4-42$.

35. Rose S, Bennuri SC, Murray KF, Buie T, Winter H, Frye RE. Mitochondrial dysfunction in the gastrointestinal mucosa of children with autism: A blinded case-control study. PLoS One 2017;12:e0186377. doi:10.1371/journal. pone. 0186377 .

36. Finegold SM. State of the art; microbiology in health and disease. Intestinal bacterial flora in autism. Anaerobe 2011;17:367-8. doi:10.1016/j.anaerobe.2011.03.007.

37. Kelly JR, Minuto C, Cryan JF, Clarke G, Dinan TG. Cross Talk: The Microbiota and Neurodevelopmental Disorders. Front Neurosci 2017;11:490. doi:10.3389/fnins.2017.00490.

38. Finegold SM. Therapy and epidemiology of autism-clostridial spores as key elements. Med Hypotheses 2008;70:508-11. doi:10.1016/j.mehy.2007.07.019.

39. Iovene MR, Bombace F, Maresca R, Sapone A, Iardino $\mathrm{P}$, Picardi A, et al. Intestinal Dysbiosis and Yeast Isolation in Stool of Subjects with Autism Spectrum Disorders. Mycopathologia 2017;182:349-63. doi:10.1007/s11046016-0068-6.

40. Persico AM, Napolioni V. Urinary p-cresol in autism spectrum disorder. Neurotoxicol Teratol 2013;36:82-90. doi:10.1016/j.ntt.2012.09.002.

41. De Angelis M, Piccolo M, Vannini L, Siragusa S, De Giacomo A, Serrazzanetti DI, et al. Fecal microbiota and metabolome of children with autism and pervasive developmental disorder not otherwise specified. PLoS One 2013;8:e76993. doi:10.1371/journal.pone.0076993.

42. Chen B, Morioka S, Nakagawa T, Hayakawa T. Resistant 
starch reduces colonic and urinary p-cresol in rats fed a tyrosine-supplemented diet, whereas konjac mannan does not. Biosci Biotechnol Biochem 2016;80:1995-2000. doi: 10.1080/09168451.2016.1194183.

43. Andriamihaja M, Lan A, Beaumont M, Audebert M, Wong $\mathrm{X}$, Yamada K, et al. The deleterious metabolic and genotoxic effects of the bacterial metabolite p-cresol on colonic epithelial cells. Free Radic Biol Med 2015;85:219-27. doi:10.1016/j.freeradbiomed.2015.04.004.

44. Karl JP, Margolis LM, Madslien EH, Murphy NE, Castellani JW, Gundersen Y, et al. Changes in intestinal microbiota composition and metabolism coincide with increased intestinal permeability in young adults under prolonged physiological stress. Am J Physiol Gastrointest Liver Physiol 2017;312:G559-G71. doi:10.1152/ajpgi.00066.2017.

45. Emanuele E, Orsi P, Boso M, Broglia D, Brondino $\mathrm{N}$, Barale $\mathrm{F}$, et al. Low-grade endotoxemia in patients with severe autism. Neurosci Lett 2010;471:162-5. doi: 10.1016/j.neulet.2010.01.033.

46. Slaughter RJ, Mason RW, Beasley DM, Vale JA, Schep LJ. Isopropanol poisoning. Clin Toxicol (Phila) 2014;52:4708. doi:10.3109/15563650.2014.914527.

47. Demehri FR, Frykman PK, Cheng Z, Ruan C, Wester T, Nordenskjold A, et al. Altered fecal short chain fatty acid composition in children with a history of Hirschsprungassociated enterocolitis. J Pediatr Surg 2016;51:81-6. doi:10.1016/j.jpedsurg.2015.10.012.

48. Murase M, Kimura Y, Nagata Y. Determination of portal short-chain fatty acids in rats fed various dietary fibers by capillary gas chromatography. $J$ Chromatogr B Biomed Appl 1995; 664:415-20.

49. Adams JB, Johansen LJ, Powell LD, Quig D, Rubin RA. Gastrointestinal flora and gastrointestinal status in children with autism--comparisons to typical children and correlation with autism severity. BMC Gastroenterol 2011;11:22. doi:10.1186/1471-230X-11-22.

50. Wang L, Christophersen CT, Sorich MJ, Gerber JP, Angley MT, Conlon MA. Elevated fecal short chain fatty acid and ammonia concentrations in children with autism spectrum disorder. Dig Dis Sci 2012;57:2096-102. doi: 10.1007/s10620-012-2167-7.

51. DeCastro M, Nankova BB, Shah P, Patel P, Mally PV, Mishra R, et al. Short chain fatty acids regulate tyrosine hydroxylase gene expression through a cAMP-dependent signaling pathway. Brain Res Mol Brain Res 2005;142:2838. doi:10.1016/j.molbrainres.2005.09.002.

52. MacFabe DF. Enteric short-chain fatty acids: microbial messengers of metabolism, mitochondria, and mind: implications in autism spectrum disorders. Microb Ecol Health Dis 2015;26:28177. doi:10.3402/mehd.v26.28177.

53. Thomas RH, Meeking MM, Mepham JR, Tichenoff L, Possmayer F, Liu S, et al. The enteric bacterial metabolite propionic acid alters brain and plasma phospholipid molecular species: further development of a rodent model of autism spectrum disorders. J Neuroinflammation 2012;9:153. doi:10.1186/1742-2094-9-153. 